Motrivivência Ano XXIV, No 38, P. 262-278 Jun./2012

http://dx.doi.org/10.5007/2175-8042.2012v24n38p270

\title{
LAZER E AS CONTRADIÇÕES SÓCIO-HISTÓRICAS DO MUNDO DO TRABALHO
}

\author{
Jeffirson Ramos da Silva' \\ Paulo Vinícius Santos Sulli Luduvice ${ }^{2}$
}

\section{RESUMO}

Diante da necessidade da construção do conhecimento e fundamentação no que diz respeito ao tema lazer, visto que o mesmo "está" presente na vida dos trabalhadores/ trabalhadoras, é que problematizamos: como o atual modo de produção e reprodução da vida humana impossibilita a contribuição do lazer no processo de humanização? Para isso levantamos como objetivo do trabalho entender como o lazer na sociedade capitalista tornou-se uma mercadoria alienante e desumanizadora. A partir da uma rápida análise (pesquisa) bibliográfica tendo a dialética como método para apreender, compreender, explicar e propor, a partir da realidade social, mudanças verdadeiramente significativas para os seres humanos.

Palavras-chave: Lazer; trabalho; alienação.

\section{ALGUMAS APROXIMAÇÕES SOBRE A ORIGEM DO LAZER}

O processo de subordinação alienação - ao capital se dá nas diversas relações de vida do ser - humano. A atual forma de sociabilidade consegue transmitir e interiorizar os seus valores dominantes capazes de alienar milhares de trabalhadores/ trabalhadoras - e desempregados/desempregadas - que sofrem dia-dia com as explorações e opressões. Sendo assim "As relações sociais determinantes, baseadas na propriedade privada capitalista e no assalariamento da

1 Licenciado em Educação Física pela Universidade do Estado da Bahia - UNEB, Pós graduado em Educação Física Escolar, atualmente é professor efetivo do município de Palmas-TO.Contato: jeffirson@hotmail.com.

2 Licenciado em Educação Física pela Universidade do Estado da Bahia - UNEB, Pós graduado em Educação Física Escolar, atualmente é professor efetivo do município de Palmas-TO.Contato: vineedfisica@hotmail.com. 
força de trabalho, gera as condições para que a atividade humana aliene em vez de humanizar". (IASI, 2007, p.21)

Desta forma, nos pautamos sobre o método Dialético para nos aproximarmos de forma mais precisa do lazer e das contradições que são engendradas pelo mundo do trabalho, para assim, apreender, compreender, explicar e propor a partir da realidade social mudanças verdadeiramente significativas para os seres humanos.

A dialética da totalidade concreta não é um método que pretende ingenuamente conhecer todos os aspectos da realidade, sem exceções, e oferecer um quadro "total" da realidade, na infinidade dos seus aspectos e propriedade; é uma teoria da realidade e do conhecimento que dela se tem como realidade. (KOSIK, 1976, p.44).

A humanidade passa por um processo de evolução/revolução, contínuo que acaba engendrando diversos fenômenos sócio-históricos que interferem na vida individual e social dos sujeitos envolvidos, por ser a sociedade um todo dialético integrado Kosik (1976).

Dentre os diversos fenômenos humanamente produzidos e historicamente acumulados, destacamos o lazer e o trabalho para uma análise mais apurada. Os mesmos têm as suas origens e definições discutidas por estudiosos de modo a caracterizá-los e situá-los no contexto dos debates científicos atribuindo-lhes grande importância.

Deste modo, dentre alguns autores que discutem lazer, trabalho e sociedade como Marcelino (1987), Melo (2003), Camargo (2003), Marx (1956), Freitas (1999), Antunes (2004), Gomes (2004), entre outros, existem duas vertentes na discussão sobre a gênese do lazer, a primeira que sustenta a origem do lazer dantes da revolução industrial, e a segunda que contrapõe e se fundamenta no advento da sociedade moderna em meados do século XVIII

Logo para fundamentar nossas assertivas nos pautamos na primeira corrente que, segundo De Grazia e Munné (apud GOMES, 2004), o fenômeno sócio-histórico que denominamos hoje como lazer precede o seu próprio conceito, pois atitudes que definimos como lazer atualmente já eram vivências antes mesmo da conceituação, e por mais que venhamos retirar este conceito, não seremos "impedidos" de vivenciá-los.

[...] não quero dizer que a prática ou a necessidade do lazer são fenômenos recentes, (...) é a partir do momento que marca o início da transição do estágio tradicional para o moderno que se verifica a ruptura entre a vida como um todo e o lazer, fazendo com que este adquira significação própria. (MARCELINO, 1995, p.20)

Segundo De Grazia (apud GOMES, 2004), se for preciso nos remeter a origem do lazer é imprescindível falarmos de Grécia, onde existia um ideal clássico do conceito que se referia à distinção social, liberdade, qualidade ética, relação com as artes e a busca pelo conhecimento.

Os romanos segundo Munné (apud GOMES, 2004), e a idade média segundo Wernerk e Bakhtin (apud GOMES, 2004) vivenciavam espaços importantes na construção do conceito de lazer. Percebemos assim que as contradições contidas na sociedade de classes, seja ela na antiguidade escravocrata, feudal ou industrial, possibilitavam o lazer por mais que fossem em momentos fugazes. 
Obviamente é questionável denominar de 'lazer' a vida social dos gregos da antiguidade. Mas, indubitavelmente, conhecer e considerar as peculiaridades daquela e de outras realidades que compõe a nossa história pode fornecer expressivas contribuições para apreendermos o processo de constituição do lazer. Afinal, é inegável que a vivencia das manifestações e tradições culturais da humanidade podem auxiliar a compreensão dos significados comumente atribuídos ao lazer em nosso contexto. (GOMES, 2004, p.137, 138).

Foi também em Roma que surgiu a preocupação com a diversão popular, - tanto quanto hoje alienada-, porém, mantendo-se a lógica da divisão de classes uma vez que as diversões da classe detentora dos meios de produção eram privilegiadas e as diversões das classes populares constituam formas de distração alienada. Inaugurava-se o que chamamos de política do "pão e circo", uma forma de dominação e controle das massas. O que ficou para os dias de hoje?

A alienação é justamente esse processo social, histórico, por meio do qual a humanidade termina por construir obstáculos nada mais são do que a desumanidade de relações sociais produzidas pelos próprios seres humanos. (LESSA e TONET, 2008, p.95).

Na Idade Média - sistema feudal de organização social - política - econômica - cultural -, a forma de diversão tem mudanças significativas apenas para a classe dominante/nobreza Munné (apud GOMES, 2004). As formas de aproveitamento do tempo livre para a classe trabalhadora/ servil continuam sendo um momento de descanso, cujo esse mesmo tempo estaria "disponível" para a reposição da força para o trabalho nos dias seguintes, mas para os nobres o lazer passa a ser um tempo de exibição social.

A Era Moderna traz consigo a implantação do modelo fabril e como consequência a intensificação da exploração/ opressão dos seres humanos pelos seres humanos,

Segundo as leis da Economia Política o estranhamento do trabalhador em seu objeto se expressa de maneira que quanto mais o trabalhador produz tanto menos tem para consumir, que quanto mais valores cria, tanto mais se torna sem valores e sem dignidade, que tanto melhor formado o se produto, tanto mais deformado o trabalhador, que tanto mais civilizado o seu objeto, tanto mais bárbaro o trabalhador, que quanto mais poderoso o trabalho, tanto mais impotente se torna o trabalhador, que quanto mais rico de espírito o trabalho, tanto mais o trabalhador se torna pobre de espírito e servo da natureza. (MARX, 2004, p.228, 229)

A partir do século XVIII faz-se ainda mais necessário o tempo de não-trabalho, surgindo assim o lazer com as características que o conhecemos hoje. Com a dimensão tomada pelo tempo de trabalho exigido a partir da Revolução Industrial, as classes populares tiveram dificuldade de se adaptarem a nova forma de organização urbana, e com isso passaram a reivindicar seus direitos que foram alcançados a partir das lutas, direitos esses que eram vistos pela burguesia como forma de desordem social.

Assim sendo, admitimos todas as contribuições do processo de Revolução industrial para a definição do que entendemos hoje como lazer, mas não coadunamos com a idéia de que o lazer é constituído a partir deste marco histórico. "Apesar de reconhecer o mérito da produção de Dumazedier e de 
outros autores que seguem seu pensamento, as evidencias indicam ser um equívoco afirmar que o lazer é um fenômeno observável apenas nas civilizações industriais avançadas" (GOMES, 2004, p.139).

É possível compreender então, que ao longo da sua história, a humanidade sempre buscou formas de divertimento diante do cansaço provocado pelo trabalho, mas essas formas de divertimento nem sempre foram - e ainda continua não sendo - consideradas como lazer, por não possuírem peculiaridades referentes a este. Para Marcellino (1995), “O lazer é visto como elemento de reforço e não de reação a alienação do homem contemporâneo, e mais ainda, como uma rentável fonte de bens e serviços a serem consumidos para alimentar o mercado". (p.13)

Para entendermos o lazer nas configurações atuais é necessário compreender que as práticas de não-trabalho sofreram/ sofrem algumas modificações ao longo da história influenciadas por fatores sócio-culturais-econômico-políticos. Sendo assim, sintetizamos a partir de dados concretos que as características fundantes do que denominamos como lazer está contido na luta entre as classes antagônicas e a atual forma de produzir, reproduzir e organizar a vida humana.

\section{O TRABALHO E O LAZER NA SOCIEDADE DE CLASSES.}

O trabalho na sociedade capitalista se configura como trabalho assalariado alienante - se sustentando na exploração do ser humano pelo ser humano, onde através deste, são produzidos bens materiais para o consumo, quem trabalha não possui o direito de usufruir do fruto do seu trabalho.
Desse modo, como denunciou Marx, os indivíduos trabalhadores - sofrem as conseqüências alienantes ao longo de toda a sua vida porque sofrem "sua degradação a mero trabalhador, sua subsunção no trabalho". Ademais, essa dependência estrutural e a correspondente degradação não é de maneira alguma o final da história. Sob determinadas circunstâncias, especialmente sob as condições de grandes crises socioeconômicas, os trabalhadores tem também de sofrer a perversidade do desemprego, a mazela cinicamente camuflada e hipocritamente justificada da "flexibilidade do trabalho" e a selvajaria da difundida precarização. Todas essas condições emergem da mesma determinação operacional do processo de trabalho capitalista. Devem-se à desumanidade irredimível da contabilidade do tempo do capital e à coação do imperativo do tempo inalterável do sistema. (MÉSZÁROS, 2008, p. 98).

Como a lógica da sociedade capitalista é transformar tudo e a todos - bens materiais e imateriais - em mercadoria, o tempo de lazer do trabalhador passou a ser mais um produto ou serviço a ser consumido de forma alienada.

É preciso ressaltar a alienação advinda do lazer, considerado simplesmente divertimento / entretenimento, a ser consumido como fuga ao esforço causado pelo trabalho alienado ou como meio para compensar as frustrações geradas pelas insatisfações ocorridas no cotidiano do indivíduo. (SÁ, 2003, p.40).

[...] o que vem aumentando nos últimos anos não é o lazer, mas o que ele denomina de 'antilazer', atividade compulsiva e realizada a partir de necessidades impostas exteriormente, com baixo grau de autonomia pessoal e autos grau de pressões e preocupações com o tempo. (GODBEY apud MARCELLINO, 1995, p. 13,14). 
Com relação ao lazer, vê-se que este não existe para a classe menos favorecia, uma vez que, para que o mesmo exista é preciso algo além de um horário de descanso ou de um momento de não trabalho, é preciso que seja retirada a barreira para ter acesso ao lazer, ou seja, primeiramente os seres humanos devem deixar de ser somente algo que produz e que consequentemente traz lucro a uma minoria.

Fica claro que para a classe de trabalhadores/trabalhadoras torna-se cada vez mais impossível a existência do lazer, mas sim a do ócio, o qual é classificado como recuperação para o trabalho por Marcellino (1987) visto que se o mesmo necessita vender sua força de trabalho é necessário também destinar um tempo de descanso e recuperação das suas energias, "Ora quais são os custos de produção da força de trabaIho? São os custos necessários para manter o operário como operário e para fazer dele um operário." (MARX, 2006, p.44). Acabando assim, por manter os meios de produção e obtenção de lucros, dos quais, jamais se apropriaram.

\section{LAZER: PRA QUE TE QUERO?}

Pode-se assistir a um jogo de futebol durante o seu tempo de lazer, e esse momento ser preenchido de valores, relações - briga entre torcidas, tristeza por seu time ter perdido, ter perdido uma aposta, felicidade por estar entre amigos - e situações que dizem respeito à formação do processo de consciência do indivíduo consequentemente a sua concepção de mundo e de sujeito,
Segundo lasi, 2007.

Falamos em processo de consciência e não apenas consciência porque não a concebemos como uma coisa que possa ser adquirida [...] Nesse sentido, procuramos entender o fenômeno consciência como um movimento e não como algo dado. Sabemos que só é possível conhecer algo se inserimos na história de sua formação, ou seja, no processo pelo qual ele se tornou o que é; assim também com a consciência: ela não 'é', 'se torna'. (p.12)

Se entendermos o lazer como o tempo de descanso e de consumo do que é ofertado no mercado, e não conseguimos entender a lógica contraditória presente no trabalho assalariado - em que o tempo de lazer é uma concessão do sistema para que sua dinâmica exploratória seja mantida estaremos fadados a alienação e submissão do capital, e continuaremos vivendo em uma sociedade em que o valor de troca se sobrepõe ao valor de uso.

A atual busca pelo lazer não está ligada as reais necessidade humanas ${ }^{3}$ dos sujeitos, nela vem embutida uma alienação ligada diretamente ao trabalho, mais especificamente a ilusão que o capital passa de sucesso profissional. Quanto mais as pessoas trabalharem melhores e maiores condições de acesso ao lazer ela vai ter - lazer que os seus patrões tem acesso e que basta cada trabalhador se esforçar eles também terão.

Essa situação social gera a ilusão, no trabalhador, de que ele compartilha de um destino comum com o capitalista. $\mathrm{O}$ crescimento da economia e do negócio

3 Necessidades humanas objetivas, aquelas que partem de necessidades concretas materiais e imateriais não para servir como especulação, consumo e lucro exacerbado. Mészáros (2008) chama as necessidades impostas pelo capitalismo de falsos apetites. 
do seu patrão parecem coincidir com os interesses do trabalhador. Este, iludido, acredita que, se a economia crescer, e se o lucro do patrão aumentar, o salário vai melhorar e os empregos serão numerosos (LESSA, TONET, 2008, p.98).

A busca por melhores condições de trabalho deve existir, pois a luta para a superação do atual modelo de sociedade se faz de forma organizada e a partir das análises e intervenções nas contradições que existem nas relações (des) humanas, para tanto, deve está ligada a um projeto popular que tenha como base a democratização da terra, democratização do capital, por entendermos que o mesmo exerce influencias direta sobre a principal força produtiva da sociedade o trabalho, democratização do meios de comunicação, cultura e da educação para assim começarmos um acumulo/ avanço fértil para uma sociedade onde não exista a exploração, opressão preconceitos e nenhuma outra forma de alienação e desumanidade.

No entanto, cabe refletir se o trabalho produz o mundo material e se essa condição deveria libertar os sujeitos, para viver, dentre outras necessidades, para o lazer; é preciso buscar a essência dessas relações nos diferentes momentos da história da humanidade, para compreender o significado do trabalho e do tempo livre para o lazer, no contexto da relações sociais de produção. Se esse contexto não permite tal possibilidade, é importante que o trabalhador reconheça quais a forças determinantes do caráter opressor; assim ele poderá lutar por um novo modelo de sistema produtivo e de sociedade, onde as relações de trabalho e lazer possam estar em equilíbrio, como condição de conquista de uma nova realidade social.(SÁ, 2003, p.45)
O modelo de lazer que está posto só pode ser superado, e ficar livre de toda a sua alienação, se a dinâmica exploratória da sociedade capitalista for extinta e a relação de trabalho e lazer tiver sentidos e significados humanos na vida de cada homem e mulher.

\section{PARA CONCLUIR SEM TERMINAR: O CONSUMO DO LAZER REGADO A QUI- MERAS}

É sobre a luz da luta de classes enquanto uma das categorias que engendra a sociedade e por consequência nos cria Peixoto (2008), é que pautamos essa discussão sobre a problemática do lazer e as suas possíveis contribuições para o processo de emancipação humana.

Logo, para darmos continuidade a discussão deste fenômeno-problema sócio-histórico é necessário (re)avivarmos duas categorias fundantes, o trabalho e as relações sociais,

Trabalhar é, portanto, conceber antecipadamente o fim que se pretende alcançar e atuar sobre a natureza para transformá-la segundo esse objetivo. Por outro lado, ao transformar a natureza, o homem cria, ao mesmo tempo, o seu próprio ser [...] [...] é por intermédio do trabalho que se realiza o salto ontológico do ser natural para o ser social. (MARX apud TONET, 2006, p.02).

Sendo assim as (im)possibilidades do "tempo livre" estão ligadas diretamente a luta de classes - condições materiais e imateriais de existência - que por conseguinte estão apontadas pelo mundo do trabalho e suas relações.

Haja vista que, o atual modo de produção, reprodução e organização da vida humana a cada instante intensifica 
a naturalização da história como uma das formas de alienação dos sujeitos históricos, para que os mesmos não percebam as possibilidades e prováveis chances das mudanças do que está posto, "os homens fazem sua própria história, mas não a fazem como querem; não a fazem sob circunstâncias de sua própria escolha, e sim sob aquelas com que se defrontam diretamente, ligadas e transmitidas pelo passado" (MARX, 1956, p.17).

No entanto, não podemos devanear sobre os terrenos inférteis das vontades, dos desejos e prazeres, acreditando que a partir da mudança apenas das atitudes para com o lazer, das mudanças pessoais ou a partir da culpabilização das vitimas do próprio processo de coisificação, iremos superar a forma do lazer alienado, que se reduz ao consumo obsessivo e obcecado de vivências sem sentidos e significados humanos, de objetos e símbolos.

Nas condições atuais, o lazer tem sido a promessa de felicidade, de prazer, abstraída da materialidade que lhe engendra e por isso não apresenta correspondência real, mas só ideal e, como é fruto de uma lógica metafísica, encobre a relação social de expropriação do trabalho produzida no seio das relações de produção capitalistas. (SOUZA, 2008, p.06).

O processo de emancipação humana no que diz respeito ao lazer não pode nem mesmo deve partir das idealizações dos seres humanos, mas sim do seu processo de vida real que tem em seu bojo a impossibilidade incontrolável e incorrigível do capital Mészáros (2008).

Logo, partindo do processo da vida real vemos e sentimos inegavelmente que não temos a liberdade da escolha, "não conseguimos" entrar em uma relação sem termos o valor de troca nos impulsionando, “Na vigência do valor de troca, o vínculo social entre as pessoas se transforma em uma relação social entre coisas: a capacidade pessoal transfigura-se em capacidade das coisas. Trata-se, portanto, de uma relação reificada entre os seres sociais" (ANTUNES, 2004, p.231).

Não podemos falar em emancipação humana sem admitir que existam fatos que a precede, se o lazer encontra-se submerso em relações quase que inteiramente capitalista que alteram em grande medida seu sentido e significado sócio-histórico e humano, fica claro que o lazer por si só, sem uma transformação radical da atual forma de sociabilidade não terá como cumprir dentro dos marcos atuais este papel de emancipar a humanidade. "A emancipação humana, ou seja, uma forma de sociabilidade na qual os homens sejam efetivamente livres, supõe a erradicação do capital e de todas as suas categorias. Sem erradicação, é impossível a construção de uma autêntica comunidade humana." (TONET, 2006, p.04).

As contradições da atual forma de sociabilidade é o que evidencia os limites e as possibilidades reais - em caráter pontual, que não terá sentido e significado humano se não estiver ligado a uma totalidade - da contribuição do lazer no processo de torna-se humano dos seres humanos. Segundo Tonet (s/d) essas contribuições para o processo só são possíveis de forma pontual por ter premissas que precede "Primeira: um grande desenvolvimento das forças produtivas, que permita a produção de bens capazes de satisfazer as necessidades de todos. Segundo: a diminuição do tempo de trabalho, de tal modo que os homens possam dedicar-se a atividades mais propriamente humanas" (TONET, 2006, p.04). 
A partir da apropriação e por consequência do acúmulo adquirido dos sujeitos históricos que nos antecederam chegamos a algumas sínteses. O lazer pode ser considerado lazer só, somente só, quando existe o direito e o conhecimento sobre as escoIhas feitas e sendo estas uma apropriação a partir do valor de uso dos bens materiais e imateriais produzidos e acumulados sócio-historicamente pela humanidade.

Explicando mais, ao se propagar que lazer seria uma atividade que se realiza por 'livre vontade' e 'prazer' - fundamentos principais dos vários conceitos expostos nas publicações - estaríamos, assim, assumindo e aceitando que é uma 'opção' pessoal. Conseqüentemente, fruto de uma 'vontade', portanto, seríamos pessoas livres e faríamos o que quiséssemos, independentemente das condições materiais existentes, ou seja, é uma questão de estilo de vida. Por outro lado, pretendem empurrar na realidade um vínculo emocional na atividade escolhida que mesmo não sendo possível existir tem que estar presente - a idéia de prazer. (SOUZA, 2009, p.06)

Todavia, devemos e podemos ir para além das anunciações e denuncias, e sim propor e construir cotidianamente junto a classe trabalhadora um projeto sócio-histórico alternativo que tenha como premissa a socialização irrestrita do solo urbano e rural, a democratozação dos meios de comunicação, da cultura, educação, do capital para assim começarmos a nos aproximar da possibilidade de um dia sermos socialmente iguais, humanamente diferentes e totalmente livres. Pois entendermos que o problema da emancipação humana não esta contido totalmente nas (im)possibilidades do lazer mais na atual forma de sociabilidade, se as discussões continuarem apenas em torno do lazer e seus limites e possibilidades estaremos nos dedicando aos falsos problemas.

\section{REFERÊNCIAS}

ANTUNES, Ricardo. Trabalho. In GOMES, Christianne Luce (Org). Dicionário Crítico do Lazer - Belo Horizonte: Autêntica, 2004

CAMARGO, Luis Octavio de Lima. O que é Lazer? São Paulo: Brasiliense, 2003. Coleção Primeiros Passos, 3.ed de 1992. FREITAS, Francismo Máuri de Carvalho. $\mathbf{O}$ livre atirador. - Vitória: UFES, Centro de Educação Física e Desporto, 1999.

GOMES, Christianne Luce. Lazer Ocorrência Histórica. In GOMES, Christianne Luce (Org). - Belo Horizonte: Autêntica, 2004.

IASI, Mauro Luis. Ensaios sobre consciência e emancipação humana. $1^{\mathrm{a}}$. Ed. - São Paulo: Expressão Popular, 2007.

KOSIK, Karel. Dialética do concreto. Rio de Janeiro: Paz e Terra, 1976.

LESSA, Sérgio, TONET, Ivo. Introdução à filosofia de Marx. $1^{\circ}$. Ed. - São Paulo: Expressão Popular, 2008.

MARCELLINO, Nelson Carvalho. Lazer e Educação. Campinas. SP: Papirus, 1987. . Lazer e humanização. $-2^{a}$

ed. - Campinas, SP - Papirus: 1995. Coleção fazer lazer.

MARX, Karl. O 18 Brumário de Luís Bonaparte. Editorial Vitória Limitada. Rio de Janeiro - 1956. . Trabalho assalariado e capital \& salário, preço e lucro. $1^{\text {a }}$. Ed. - São Paulo: Expressão Popular, 2006. - Trabalho estranhado e propriedade privada. In ANTUNES, Ricardo (org). A dialética do trabalho: 
escritos de Marx e Engels. - São Paulo:

Expressão Popular, 2004.

MELLO. Vitor Andrade de. Introdução ao

lazer. Barueri, SP. Manole, 2003.

MÉZÁROS, István. A educação para

além do capital. $2^{\mathrm{a}}$. Ed. - São Paulo:

Boitempo, 2008.

PEIXOTO, Elza. Estudo da Categoria Modo

de Produção da Existência na Obra de Marx e Engels e suas Implicações para a Compreensão da Problemática do Lazer. Boletim do Grupo de Estudos e Pesquisa Marxismo, História, Tempo Livre e Educação (MTTLE) Boletim número 4, 10/2008. Disponível em: < http:// www.uel.br/grupo-pesquisa/ mhtle/index.htm/ > Acesso em: 16 de jul.2008.

SA, de Oliver Kátia. Lazer, trabalho e educação: pressupostos ontológicos dos estudos do lazer no Brasil. Boletim do Grupo de Estudos e Pesquisa Marxismo, História, Tempo Livre e Educação
(MTTLE) Boletim número 4, 10/2008.

Disponível em: <http:// www.uel.br/ grupo-pesquisa/mhtle/index.htm/ > Acesso em: 16 de jul.2008.

SOUZA, Iracema Soares de. O lazer e a ilusão liberal. Boletim do Grupo de Estudos e Pesquisa Marxismo, História, Tempo Livre e Educação (MTTLE) Boletim número 4, 10/2008. Disponível em: <http:// www.uel.br/ grupo-pesquisa/mhtle/index.htm/ > Acesso em: 16 de jul.2008.

TONET, Ivo. Educação e formação humana. 2006 Endereço < http://www. geocities.com/ivotonet/ > acessado em: 15/10/2008.

. Cidadania ou Emancipação Humana. S/D. Endereço < http://www. geocities.com/ivotonet/ $>$ acessado em:15/10/2008.

Mercado e Liberdade. S/D. Endereço < http://www.geocities.com/ ivotonet/> acessado em:15/10/2008.

\title{
CONTRADICTIONS LEISURE AND SOCIAL-HISTORICAL WORLD OF WORK
}

\begin{abstract}
Given the necessity of building the knowledge and reasoning with to the subjetc leisure, since the name "is" present in the lives of workes/laborers, is that we question, as the current mode of procuction and reproduction of human lifeprecludes the contribution leisure in the process of humanization? To raise this is a goal of working to understand how leisure in capitalist sociaty has become a commodity alienanting and dehumanizing. From a quick analysis (research) literature with the dialetic as a method to learn, understand, exmplain and propose changes from the social reality truly meaningful to humans.
\end{abstract}

Keywords: business; labor; disposal. 